\title{
Enzymatic process optimization for the in vitro production of isoprene from mevalonate
}

\author{
Tao Cheng ${ }^{1,3+}{ }^{+}$Hui Liu ${ }^{1 \dagger}$, Huibin Zou ${ }^{1,2^{*}}$, Ningning Chen ${ }^{2}$, Mengxun Shi ${ }^{2}$, Congxia Xie ${ }^{3}$, Guang Zhao ${ }^{* *}$ \\ and Mo Xian ${ }^{1 *}$
}

\begin{abstract}
Background: As an important bulk chemical for synthetic rubber, isoprene can be biosynthesized by robust microbes. But rational engineering and optimization are often demanded to make the in vivo process feasible due to the complexities of cellular metabolism. Alternative synthetic biochemistry strategies are in fast development to produce isoprene or isoprenoids in vitro.
\end{abstract}

Results: This study set up an in vitro enzyme synthetic chemistry process using 5 enzymes in the lower mevalonate pathway to produce isoprene from mevalonate. We found the level and ratio of individual enzymes would significantly affect the efficiency of the whole system. The optimized process using 10 balanced enzyme unites $(5.0 \mu \mathrm{M}$ of MVK, PMK, MVD; $10.0 \mu \mathrm{M}$ of IDI, $80.0 \mu \mathrm{M}$ of ISPS) could produce $6323.5 \mu \mathrm{mol} / \mathrm{L} / \mathrm{h}$ (430 mg/L/h) isoprene in a $2 \mathrm{ml}$ in vitro system. In a scale up process (50 ml) only using 1 balanced enzyme unit ( $0.5 \mu \mathrm{M}$ of MVK, PMK, MVD; $1.0 \mu M$ of IDI, $8.0 \mu \mathrm{M}$ of ISPS), the system could produce $302 \mathrm{mg} / \mathrm{L}$ isoprene in $40 \mathrm{~h}$, which showed higher production rate and longer reaction phase with comparison of the in vivo control.

Conclusions: By optimizing the enzyme levels of lower MVA pathway, synthetic biochemistry methods could be set up for the enzymatic production of isoprene or isoprenoids from mevalonate.

Keywords: Mevalonate, Isoprene, Synthetic biochemistry, Isoprenoids, Bio-based chemicals, Enzymatic process

\section{Background}

Commodity chemicals are traditionally produced from petroleum via the energy-intensive chemical methods. Alternative process that does not rely on the petroleum resources and chemo-process is under fast development for chemical production, using the advanced tools of synthetic biology and metabolic engineering $[1,2]$. Recently, isoprene and a variety of isoprenoids can be produced from renewable feedstock through engineered microbes [3-7]. The general strategy is engineering the whole isoprenoid biosynthesis pathways in the chassis strains [6], and the mevalonate (MVA) pathway other than the methylerythritol 4-phosphate (MEP) pathway is usually

\footnotetext{
*Correspondence: huibinzou@hotmail.com; zhaoguang@qibebt.ac.cn; xianmo@qibebt.ac.cn

†Tao Cheng and Hui Liu contributed equally to the work

${ }^{1}$ CAS Key Laboratory of Bio-based Materials, Qingdao Institute of Bioenergy and Bioprocess Technology, Chinese Academy of Sciences, No. 189 Songling Road, Laoshan District, Qingdao 266101, China Full list of author information is available at the end of the article
}

selected to construct robust strains with higher production titers [8].

However, the biosynthesis of isoprene and isoprenoids by the cell-based strategy faced one major bottleneck: the nutrient limitation and the accumulation of toxic intermediates or products may lead to cell growth inhibition and limited yields and titers; thus rational engineering and optimization are often demanded to make the process economically feasible [9-12]. Corresponding synthetic biochemistry tool has also been demonstrated to overcome the major bottleneck of the cell-based strategy, especially in rational optimization of synthetic multienzyme pathways [13]. The emergence of cell-free system has several advantages over the cell-base system: (1) process can be operated continuously; (2) can synthesize hazard products which are toxic towards living cell system; (3) enzyme can be quantitatively and biochemically adjusted to optimize flux through the metabolic pathways; (4) reduce the operation (like gas-stripping) and 
purification requirements; (5) higher yields without competing cellular pathways. In case of isoprene biosynthesis, a recent cell-free approach for the conversion of the glycolysis intermediate phosphoenolpyruvate into isoprene at nearly $100 \%$ molar yield was promoted [14]. The in vitro system involves enzymes through the full MVA pathway. While challenges also exist for the synthetic biochemistry platform, as the cofactors of ATP, NADPH, and acetylCoA need to be balanced in the complex MVA pathway: NADPH and acetyl-CoA are involved in the upper MVA pathway (from pyruvate to MVA), ATP is involved in the lower MVA pathway (from MVA to isoprene). Thus additional enzymes are needed to balance the supply/consumption of these co-factors which increased the total enzymes of 12 in the complex in vitro system for bioisoprene $[13,14]$.

This study focused on implementing an enzymatic process only consisting of lower MVA pathway for the biosynthesis of isoprene directly from MVA. In the demonstrated system, the cofactors of NADPH and acetylCoA are not involved, which decreases the needs of additional enzymes to balance these factors. Moreover, the enzyme activities and quantities of the simplified system (only involves 5 enzymes) can be easily and precisely adjusted to optimize flux through the biochemical steps, which would improve the conversion efficiency comparing to the current in vitro platform for bioisoprene.

\section{Results and discussion}

Purification of the enzymes in lower MVA pathway

In this study, four biosynthetic enzymes of lower MVA pathway and isoprene synthase were individually prepared by recombinant E. coli strains (Table 1) and purified before in vitro production. Through these enzymes mevalonate can be converted to dimethylallyl pyrophosphate (DMAPP) by primary mevalonate kinase (MVK, EC 2.7.1.36) and secondary phosphorylation (phosphomevalonate kinase, PMK, EC 2.7.4.2), decarboxylation (diphosphomevalonaet decarboxylase, MVD, EC 4.1.1.33) and isomerization (isopentenyl diphosphate isomerase, IDI, EC 5.3.3.2), then the isoprene synthase (ISPS, EC 4.2.3.27) catalyzes the formation of isoprene from DMAPP. For each molecular of isoprene from MVA, 3 ATP is needed and NADPH is not demanded for the in vitro bioconversion, which is different with the in vivo system from pyruvate $[14,15]$. In order to prevent the formation of inclusion body and ensure correct enzyme folding, each enzyme was purified and checked

Table 1 Bacterial strains and plasmids used in this study

\begin{tabular}{|c|c|c|}
\hline Strain/plasmid/primer & Relevant genotype/property/sequence & Source/reference \\
\hline \multicolumn{3}{|l|}{ Strains } \\
\hline E. coli BL21(DE3) & $\mathrm{F}^{-}$ompThsdS ${ }_{B}\left(r_{B}^{-} m_{B}^{-}\right)$gal dcm rne131 (DE3) & Invitrogen \\
\hline MVK producer & $\mathrm{BL} 21(\mathrm{DE} 3) / \mathrm{pET}-\mathrm{ERG} 12$ & This study \\
\hline MVD producer & BL21(DE3)/pET-ERG8 & This study \\
\hline PMK producer & BL21(DE3)/pET-ERG19 & This study \\
\hline IDI producer & BL21(DE3)/pET-IDI & This study \\
\hline ISPS producer & BL21(DE3)/pET-ISPS & This study \\
\hline \multicolumn{3}{|l|}{ Plasmids } \\
\hline pYJM14 & pTrCHis2B derivative carryinggenes ERG8, ERG12, ERG19 and IDI, Trc promoter, $\mathrm{Ap}^{\mathrm{R}}$ & [16] \\
\hline pET-ERG12 & pET30a(+) derivative carryinggenes gene ERG12,T7 promoter, $\operatorname{Kan}^{\mathrm{R}}$ & This study \\
\hline pET-ERG8 & pET30a(+) derivative carryinggenes gene ERG8, T7 promoter, Kan $^{R}$ & This study \\
\hline pET-ERG19 & pET30a(+) derivative carryinggenes geneERG19, T7 promoter, $\mathrm{Kan}^{\mathrm{R}}$ & This study \\
\hline pET-IDI & pET30a $(+)$ derivative carryinggenes gene IDI, T7 promoter, $\mathrm{Kan}^{\mathrm{R}}$ & This study \\
\hline pET-ISPS & pET30a(+) derivative carryinggenes gene ISPS, T7 promoter, Kan $^{R}$ & This study \\
\hline PACY-ISPS & pACYDuet-1 derivative carryinggenes gene ISPS, T7 promoter, $\mathrm{Cm}^{\mathrm{R}}$ & This study \\
\hline \multicolumn{3}{|l|}{ Primers } \\
\hline ERG12_F & 5'-CCCAAGCTTGGTCATTACCGTTCTTAACTTC-3' & \\
\hline ERG12_R & 5'-CCGCTCGAGTTATGAAGTCCATGGTAAAT-3' & \\
\hline ERG8_F & 5'-CCGGAATTCTCAGAGTTGAGAGCCTTCAG-3' & \\
\hline ERG8_R & 5'-CCGCTCGAGTTATTTATCAAGATAAGTTT-3' & \\
\hline ERG19_F & 5'-CGCGGATCCACCGTTTACACAGCATCCGT-3' & \\
\hline ERG19_R & 5'-CCGCTCGAGTTATTCCTTTGGTAGACCAG-3' & \\
\hline IDI_F & 5'-CGCGGATCCACTGCCGACAACAATAGTAT-3' & \\
\hline$|D| \_R$ & 5'-CCGCTCGAGTTATAGCATTCTATGAATTT-3' & \\
\hline
\end{tabular}


their molecular size by SDS-page before enzymatic assay experiments. We found that keeping the cultures at $20^{\circ} \mathrm{C}$ after IPTG induction in the fermentation process helped to improve the yield of soluble recombinant enzymes. The purity and molecular size of the purified enzymes can be seen in Fig. 1.

\section{In vitro production of isoprene from mevalonate}

With the purified enzymes, we further tested whether the lower mevalonate pathway can be reconstituted in vitro by mixing of substrate and ATP with the purified enzymes. The addition of ATP is compulsory as three ATP are used in the phosphorylation and decarboxylation of mevalonate to IPP (Fig. 1). In the $2 \mathrm{ml}$ in vitro system with purified enzymes $(0.5 \mu \mathrm{M}$ each), substrate $(2.5 \mathrm{mM})$ and ATP $(12 \mathrm{mM})$, we took samples and analyzed total isoprene at different time points and calculate the rate of reaction (total isoprene/L/h) at the different time points. The results showed that the maximum isoprene production $(76.5 \mu \mathrm{mol} / \mathrm{L} / \mathrm{h}, 5.2 \mathrm{mg} / \mathrm{L} / \mathrm{h})$ occurred at $4 \mathrm{~h}$ after the addition of ATP and mevalonate (Fig. 2a), similar with the time course curve of in vitro isoprene production from PEP in the previous study [14].

We next tested the optimum mevalonate/ATP ratio in the $2 \mathrm{ml}$ in vitro system. The optimum concentration of mevalonate (substrate) was analyzed by starting with a fixed amount of ATP $(12 \mathrm{mM})$ and sequentially increasing amount of mevalonate (Fig. 2b). The results showed that the maximum isoprene production was achieved when $2.5 \mathrm{mM}$ mevalonate was added in the system, and the isoprene production was decreased when the initial concentration of mevalonate was over $2.5 \mathrm{mM}$. We also tested the optimum concentration of ATP with fixed amount of mevalonate $(2.5 \mathrm{mM})$. The results showed that supplementation of $10 \mathrm{mM}$ ATP resulted in the maximum isoprene production (Fig. 2c). The production of isoprene was increasing with the increasing of ATP from 2 to $12 \mathrm{mM}$, it is suggested that the lower pathway of MVA was inhibited when the concentration of substrate of mevalonate was higher than $2.5 \mathrm{mM}$. The optimum ratio for substrate (mevalonate) and cofactors (ATP) is around 1:4, which is excess to the theoretical

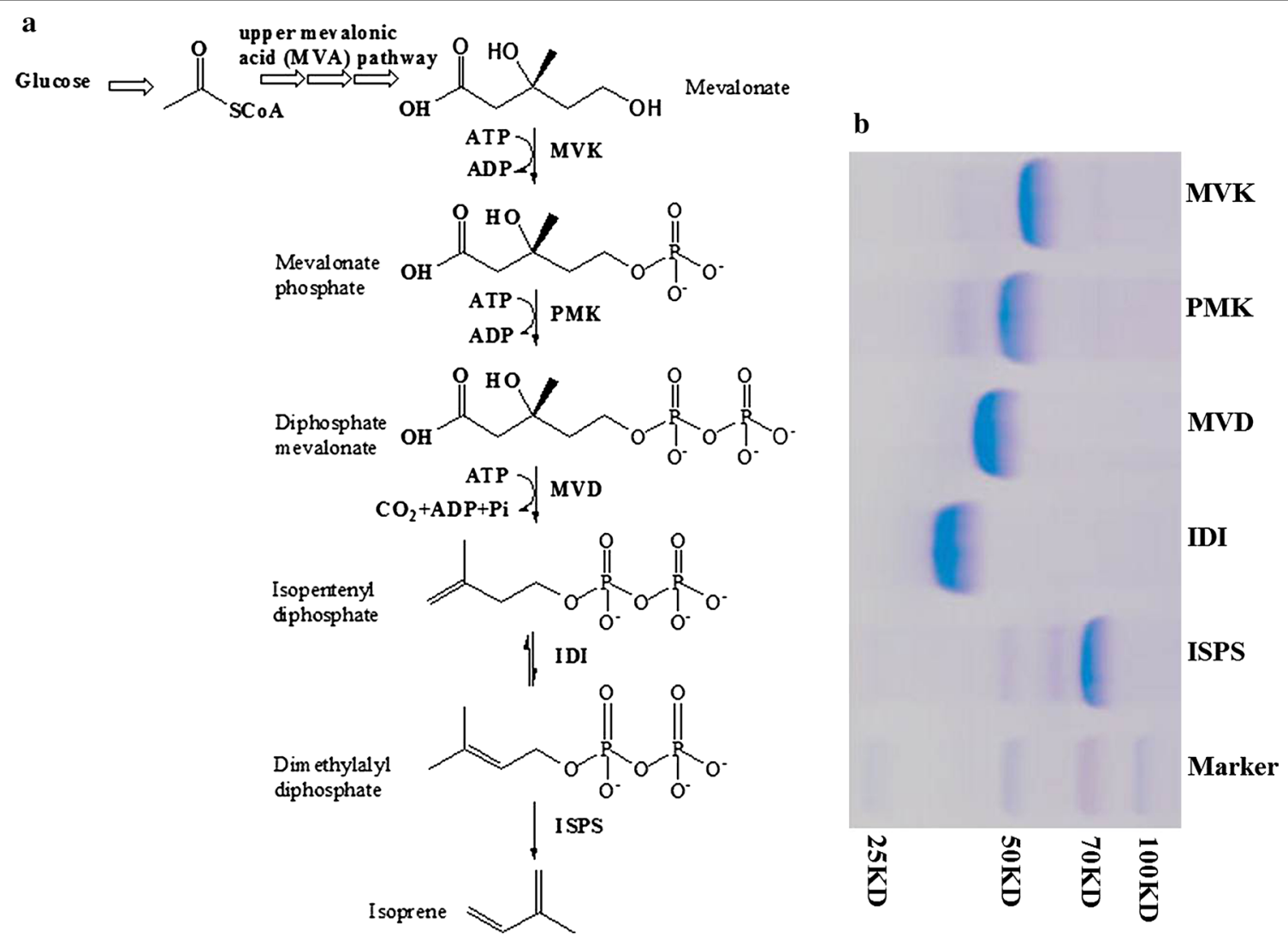

Fig. 1 The purified enzymes of the lower MVA pathway. a Pathway overview. The lower MVA pathway consists of 5 enzymatic reactions each catalyzed by MVK (mevalonate kinase, EC 2.7.1.36), PMK (phoshpomevalonate kinase, EC 2.7.4.2), MVD (diphoshpomevalonate kinase, EC 4.1.1.33), IDI (isopentenyl diphosphate isomerase, EC 5.3.3.2) and ISPS (isoprene synthase, EC 4.2.3.27). b The size of the purified enzymes 

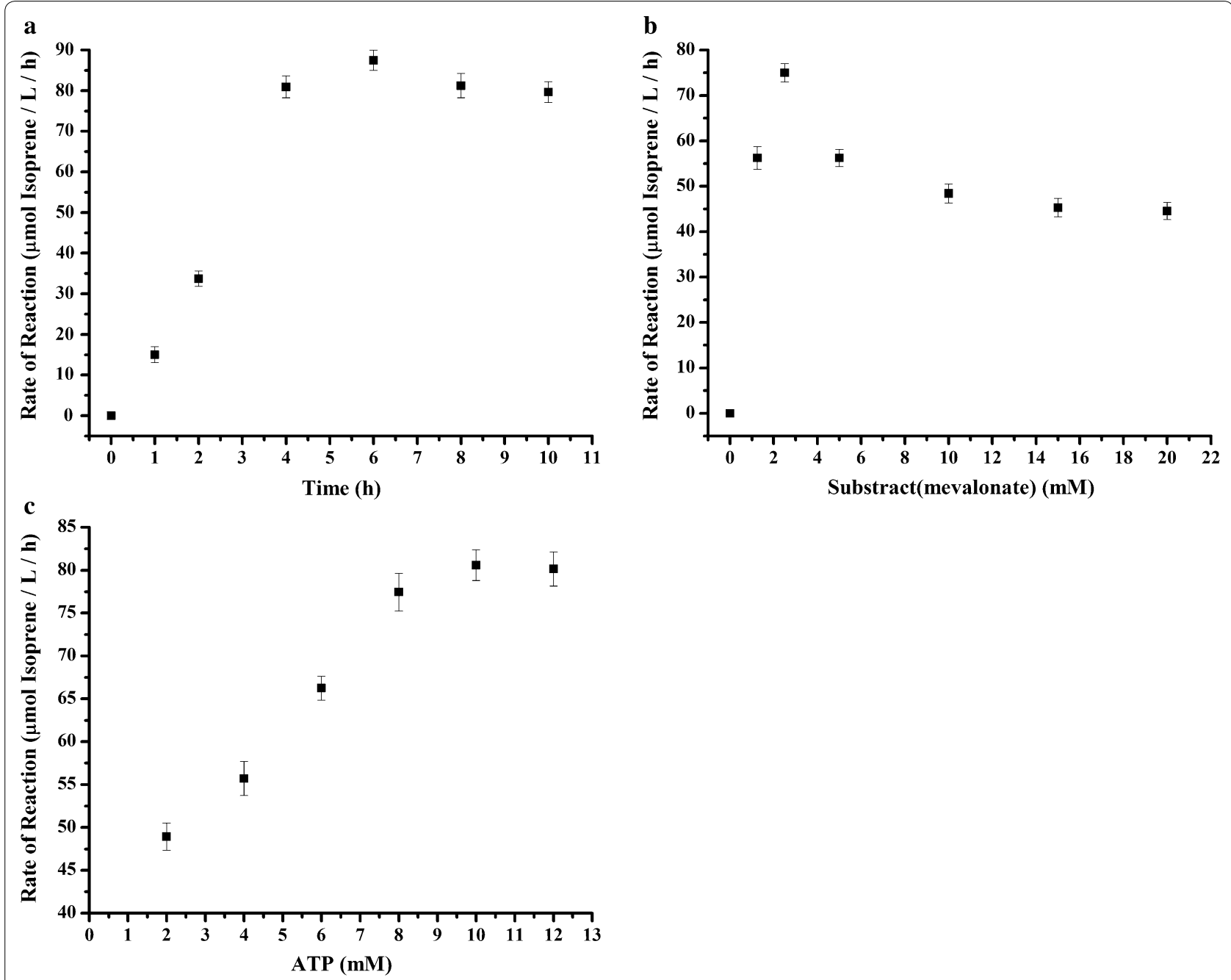

Fig. 2 Determination of the optimal enzymatic conditions. The production rate of isoprene in $2 \mathrm{ml}$ enzymatic system under conditions: a $2.5 \mathrm{mM}$ mevalonic acid, $12 \mathrm{mM}$ ATP, with varied reaction time; b $12 \mathrm{mM}$ ATP, reaction for $4 \mathrm{~h}$, with varied concentration of mevalonic acid; $\mathbf{c} 2.5 \mathrm{mM}$ mevaIonic acid, reaction for $4 \mathrm{~h}$, with varied concentration of ATP. The data shown are means of three repeated experiments and the error bars present the standard deviation

ATP consumption (1:3) in the lower mevalonate pathway (Fig. 1). The excess addition of ATP is similar with previous study when acetyl-CoA was utilized as substrate for the in vitro production of isoprene [14].

\section{Quantitatively balancing enzyme levels to maximum the isoprene production}

In the in vitro isoprene biosynthesis system, the enzyme quantity can be precisely adjusted to optimize the flux through the biochemical steps comparing with the isoprenoids biosynthesis using living cells, in which promoter induction is often highly cooperative and fine control is difficult [11]. To quantitatively construct balanced in vitro system, we firstly screened the bottleneck enzymes which significantly affect the isoprene production. The effects of enzyme levels towards isoprene production were tested by varying the levels between 0.02 and $5 \mu \mathrm{M}$ with the constant levels of other four enzymes at $0.5 \mu \mathrm{M}$ (Fig. 3a) in the $2 \mathrm{ml}$ in vitro system. The results showed that the enzymes had different effects towards the isoprene production. PMK and MVD were not belonging to the bottleneck enzymes in the pathway, as their levels did not significantly influence the isoprene production. For the enzymes of MVK and IDI, their increasing levels generated a 30-90\% increase in isoprene production: MVK reached the maximum isoprene production at the level of $0.5 \mu \mathrm{M}$ while IDI reached the maximum isoprene production at $1.0 \mu \mathrm{M}$ (Fig. 3a). The last enzyme of ISPS, which catalyzes the production of isoprene from DMAPP, belonged to the bottleneck 


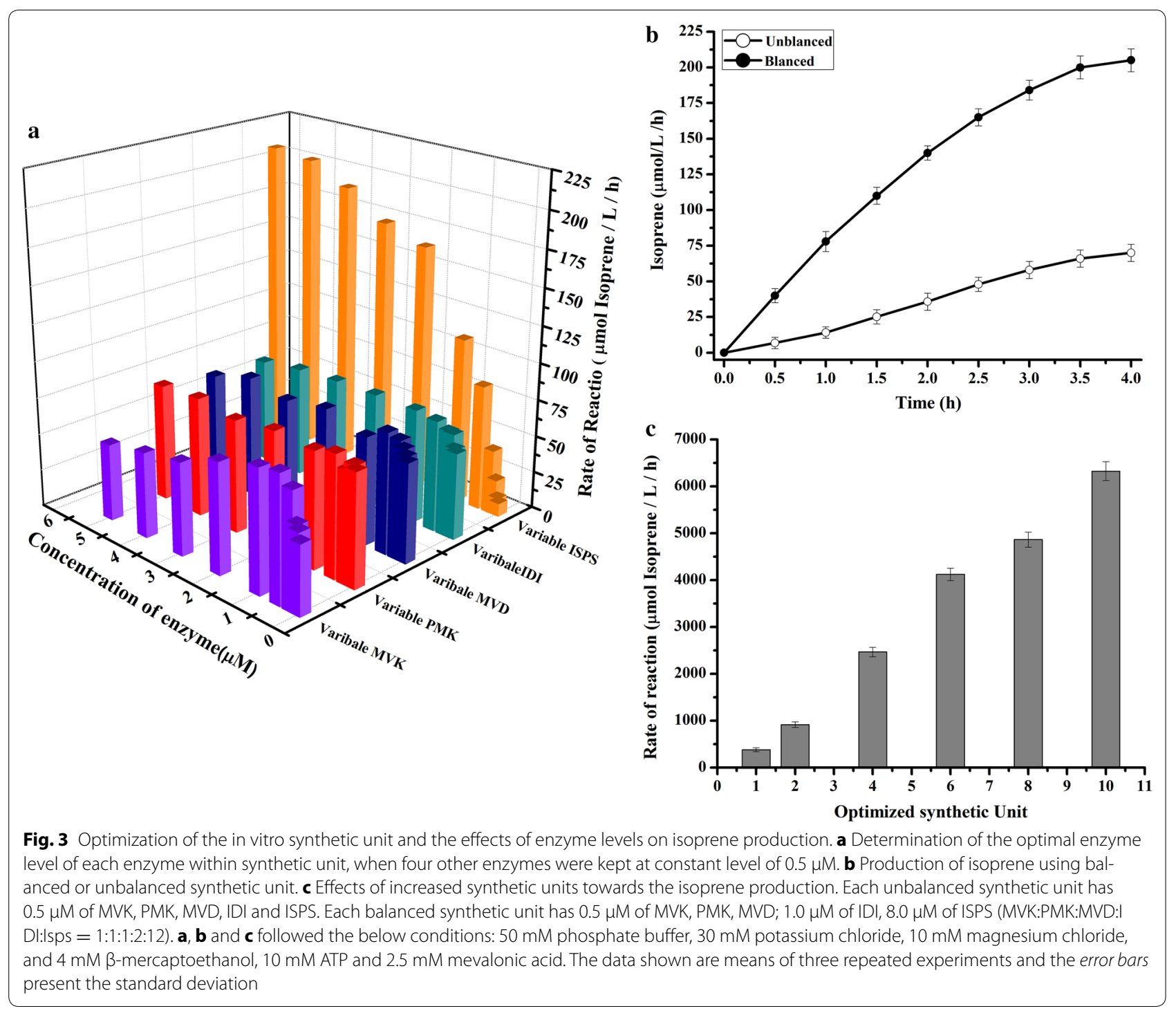

enzyme of this in vitro system, as its increasing levels from 0.02 to $5 \mu \mathrm{M}$ gave a 30 -fold increase in isoprene production. The results indicated that IDI and ISPS were two bottleneck enzymes in the in vitro production of isoprene from mevalonate, and their levels needed to be adjusted to balance the in vitro system. From the data of Fig. 1a, we could deduce that the optimized molarity ratio of MVK: PMK: MVD: IDI: ISPS was 1:1:1:2:16. One such balanced synthetic unit $(0.5 \mu \mathrm{M}$ of MVK, PMK, MVD; $1.0 \mu \mathrm{M}$ of IDI, $8.0 \mu \mathrm{M}$ of ISPS) could produce up to $382.4 \mu \mathrm{mol} / \mathrm{L} / \mathrm{h}(26 \mathrm{mg} / \mathrm{L} / \mathrm{h})$ isoprene, which is nearly five folds of the isoprene production by the unbalanced synthetic unit $(0.5 \mu \mathrm{M}$ of each enzyme, Fig. $3 \mathrm{~b})$. Moreover, when multiple synthetic unit is supplemented in the $2 \mathrm{ml}$ in vitro system, the production efficiency of isoprene could be significantly improved, 10 balanced synthetic units $(5.0 \mu \mathrm{M}$ of MVK, PMK, MVD; $10.0 \mu \mathrm{M}$ of IDI, $80.0 \mu \mathrm{M}$ of ISPS) would increase the isoprene production to $6323.5 \mu \mathrm{mol} / \mathrm{L} / \mathrm{h}(430 \mathrm{mg} / \mathrm{L} / \mathrm{h})$ (Fig. 3c).

Our results demonstrated that balancing of enzyme levels could significantly increase the in vitro production of isoprene, which followed the results of in vivo studies that the balanced expression levels of heterologous enzymes is a key determinant in optimizing isoprenoid production $[10,11]$. The in vivo studies aim to balance the heterologous pathways to reduce the growth inhibition effects towards the microbial hosts while the in vitro studies more focus on overcoming the limiting biochemical steps in heterologous flux towards the objective products. For example, we have noted that the enzymes levels of MVK did not apparently affect the in vitro production of isoprene (Fig. 3a) and they were kept at minimum level 
$(0.5 \mu \mathrm{M})$ in our balanced synthetic unit. While in the in vivo studies for isoprene $[3,16]$ and isoprenoids biosynthesis [11], the expression of MVK were adjusted at higher levels, in which MVK was believed to be a key enzyme and was expressed by stronger promoters than PMK and MVD. We hypothesized that the in vivo system has specific mechanism to adjust the intra- and extracellular levels of mevalonate (MVA), and higher level of MVK helps to convert the intracellular MVA before it is transported off the cell. The last enzyme ISPS were both found bottleneck enzyme in previous study [17] as well as in this study. From the data of this study, ISPS catalyzed the rate-limiting biochemical step in heterologous flux from DMAPP to the isoprene. The in vivo models also supported this conclusion, it was proved that lower expression level of key enzyme downstream the IPP/DMAPP will lead to the accumulation of C5 building blocks (IPP and DMAPP), and will inhibit normal cell growth [9].

Comparing with the previous in vitro experiment [14] which incorporated as much as 12 enzymes of upper and lower MVA pathways, this study demonstrated a simpler system which only involved 5 enzymes and their levels were precisely adjusted to optimize flux through the biochemical steps. After optimization, the isoprene production was significantly improved (from 214.5 to $6323.5 \mu \mathrm{mol} / \mathrm{L} / \mathrm{h}$ ) comparing with the previous in vitro experiment [14].

\section{In vitro and in vivo production of isoprene from MVA: a comparison}

We further set up a $50 \mathrm{ml}$ in vitro system and compared its isoprene production with the in vivo flask fermentation $(50 \mathrm{ml})$, from the same starting concentration of mevalonate substrate. The results showed that the in vitro model apparently had higher isoprene production rate than the in vivo model during the earlier $12 \mathrm{~h}$ of isoprene production (Fig. 4). The initial isoprene production rate is about $220.6 \mu \mathrm{mol} / \mathrm{L} / \mathrm{h}(15.0 \mathrm{mg} / \mathrm{l} / \mathrm{h}$, total $160 \mathrm{mg} / \mathrm{l}$ isoprene within $12 \mathrm{~h}$ ), which is similar with the recent study for the in vitro isoprene production system [14]. Moreover, isoprene production remained longer for the in vitro system: from 20 to $40 \mathrm{~h}$, the production of isoprene was suspended in the in vivo system, but was consistent in the in vitro system. Until $40 \mathrm{~h}$, the production of isoprene from mevalonate by the in vitro system reached to $4442.4 \mu \mathrm{mol} / \mathrm{L}(302.0 \mathrm{mg} / \mathrm{l})$. From the comparison of the isoprene production by the in vitro and the in vivo models, we could deduce that the balanced in vitro enzyme system led to higher production rate and prolonged isoprene production. We estimated that the unbalanced intracellular enzymes levels, accumulated toxic intermediates, competitive consumption of co-factors may affect the isoprene production by the in vivo methods.

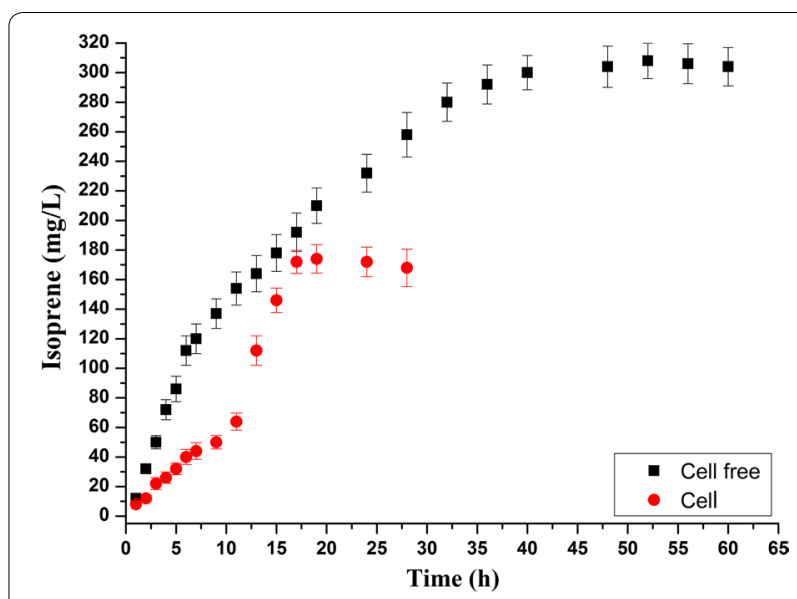

Fig. 4 The comparison of isoprene production by $50 \mathrm{ml}$ in vitro and in vivo systems. The concentration of MVK $(0.5 \mu \mathrm{M})$ was similar in both in vitro (black) and in vivo (red) systems. The cell free in vitro system has 1 synthetic unit ( $0.5 \mu \mathrm{M}$ of MVK, PMK, MVD; $1.0 \mu \mathrm{M}$ of IDI, $8.0 \mu \mathrm{M}$ of ISPS) with $50 \mathrm{mM}$ phosphate buffer, $30 \mathrm{mM}$ potassium chloride, $10 \mathrm{mM}$ magnesium chloride, and $4 \mathrm{mM} \beta$-mercaptoethanol. $50 \mathrm{ml}$ culture of engineered E. coli (BL21(DE3)/pYJM14/pACY-ISPS,

Table 1) which expressed the five enzymes of the lower MVA pathway was utilized as the in vivo control. Both systems was initiated by addition of $2.5 \mathrm{mM}$ mevalonic acid and incubated at $30^{\circ} \mathrm{C}$ in rotary shaker (180 rpm). Samples were taken to analyze their isoprene production at different time points. The data shown are means of three repeated experiments and the error bars present the standard deviation

\section{Conclusion}

In this study, isoprene was produced from mevalonate by an optimized enzymatic process using the five recombinant enzymes of MVK, PMK, MVD, IDI and ISPS from the lower MVA pathway. Balancing and increasing the enzyme levels could apparently enhance isoprene production, indicated that the production rate could be further increased by raising the concentrations of the mevalonate and enzymes, which is hard to achieved by the in vivo approaches. When the balanced enzyme units were increased to ten, the proposed process would produce $6323.5 \mu \mathrm{mol} / \mathrm{L} / \mathrm{h}(430 \mathrm{mg} / \mathrm{L} / \mathrm{h}$ in a $2 \mathrm{ml}$ system $)$ isoprene from mevalonate. Moreover, this study showed that the proposed process has the advantages of longer producing period of $40 \mathrm{~h}$ comparing with the controlled in vivo process. The improved production efficiency indicated that the proposed strategy is useful for the enzymatic production of isoprene or isoprenoids.

\section{Methods}

\section{Strains and plasmids}

Bacterial strains and plasmids used in this study were listed in Table 1. Escherichia coli strain DH5 $\alpha$ and BL21 (DE3) and Saccharomyces cerevisiae used in this study were purchased from Invitrogen. The E. coli DH5 $\alpha$ strain and E. coli BL21 (DE3) were used for plasmids 
preparation and for protein overexpression respectively. S. cerevisiae was used for gene for cloning. E. coli DH5 $\alpha$ and E. coli BL21 (DE3) were cultured in Luria-Bertani (LB) broth in construction of strains and plasmids. S. cerevisiae was cultured in YPD medium. Antibiotics were added at final concentration of $50 \mu \mathrm{g} / \mathrm{mL}$ for kanamycin, $34 \mu \mathrm{g} / \mathrm{mL}$ for chloramphenicol and $100 \mu \mathrm{g} / \mathrm{mL}$ for ampicillin when necessary.

\section{Protein preparation and purification}

All PCRs were done using PrimerSTAR Max DNA polymerase (TAKARA, Dalian, China). Four genes of the enzymes MVK, PMK, MVD, IDI were amplified from $S$. cerevisiae genome (obtained from ATCC201508D) and cloned into the plasmid pET-30a $(+)$. The plasmid pETERG12 was constructed by cloning the ERG12 gene (for MVK) of S. cerevisiae into HindIII and XhoI sites of vector pET-30a(+) with primers ERG12_F and ERG12_R. The plasmid pET-ERG8 was constructed by cloning the ERG8 gene (for PMK) from S. cerevisiae into EcoRI and XhoI sites of vector pET-30a(+) with primers ERG8_F and ERG8_R. The plasmid pET_ERG19 was constructed by cloning the ERG19 gene (for MVD) from S.cerevisiae into BamHI and XhoI sites of vector pET-30a $(+)$ with primers ERG19_F and ERG19_R. The fourth gene for enzyme IDI was amplified by PCR using primers IDI_F and IDI_R and cloned into BamHI and XhoI sites of vector pET-30a $(+)$. The resulting plasmid was named pET-IDI. The isoprene synthase (ISPS) from poplar was synthesized after code optimization and digested with enzymes BamHI and XhoI, then ligated into the pET$30 \mathrm{a}(+)$, the resulting plasmid was named pET-ISPS (Table 1).

Individual recombinant enzymes were extracted and purified from the strains of E.coli BL21(DE3) harboring the relevant plasmids. The cultures were incubated in $200 \mu \mathrm{ml} \mathrm{LB}$ medium with $50 \mu \mathrm{g} / \mathrm{ml}$ Kanamycin at $37{ }^{\circ} \mathrm{C}$ until the OD600 reached $0.6-0.8$. The cultures were added $0.2 \mathrm{mM}$ IPTG for induction and were cooled to $20{ }^{\circ} \mathrm{C}$ for protein expression. After further growth at $20{ }^{\circ} \mathrm{C}$ for $12 \mathrm{~h}$, cells were harvested by centrifugation at $8000 \mathrm{~g}$ and suspended in $10 \mathrm{~mL} 50 \mathrm{mM}$ phosphate buffer (pH7.4) containing $4 \mathrm{mM} \beta$-mercaptoethanol. The suspension was lysed by sonication (at $60 \%$ output for $3 \mathrm{~s}$ pulses with $3 \mathrm{~s}$ intervals between each cycle) for $40 \mathrm{~min}$ at $4{ }^{\circ} \mathrm{C}$ with tube jacketed in wet ice and centrifuged at $18,000 \mathrm{~g}$ for $10 \mathrm{~min}$ at $4{ }^{\circ} \mathrm{C}$. The supernate filtered by $0.22 \mu \mathrm{m}$ PALL filter was added into the Nickel Column, which was washed by $10 \mathrm{ml}$ water and $10 \mathrm{ml}$ binding buffer in order to ensure that the column was equilibrated, and then the protein containing 6 His-tag was able to specifically bind to nickel column. Unbound protein was washed out with $10 \mathrm{ml}$ washing buffer 1 , then washing Buffer 2 was used to wash any nonspecific binding protein. Elution buffer was added to wash the specific protein with collection of $10 \mathrm{ml}$ fractions. The column was then re-equilibrated with buffer. Protein concentrations were measured with BCA protein assay kit using a spectrophotometer. Recombinant enzymes were stored at $-80^{\circ} \mathrm{C}$ after flash freezing in liquid nitrogen.

\section{In vitro reaction system}

The reaction system was performed as previously described [18] to ensure the correct concentration of individually enzyme. For the demonstrated assay, a variety levels of each enzyme component and ATP were added to the reaction buffer which contain $50 \mathrm{mM}$ potassium phosphate, $30 \mathrm{mM}$ potassium chloride, $10 \mathrm{mM}$ magnesium chloride, and $4 \mathrm{mM} \beta$-mercaptoethanol. The reaction was initiated by addition of $2.5 \mathrm{mM}$ mevalonic acid which was made by the saponification of mevalonolactone with $\mathrm{KOH}$ at 1.05:1 (vol:vol) $\mathrm{KOH}$ :mevlonolactone for $30 \mathrm{~min}$ at $37{ }^{\circ} \mathrm{C}$, and then incubated at $30{ }^{\circ} \mathrm{C}$ for $4 \mathrm{~h}$. To confirm isoprene had accumulated in the $2 \mathrm{ml}$ reaction system, $0.2 \mathrm{ml}$ of the headspace gas of sealed $10 \mathrm{ml}$ vial were analyzed by gas chromatography using Agilent 7890B GC (Agilent, American) equipped with a flame ionization detector and a Agilent HP-INNWOX column, designed to detect short-chain hydrocarbons. Amounts of isoprene produced in the recombinant system were calculated by comparison with an isoprene standard (Aladdin, China).

\section{Gas chromatography (GC) analysis of isoprene}

$1 \mathrm{ml}$ of off-gas samples from the headspace of the fermentor were analyzed as described earlier [16] using a GC (Agilent 7890A, America) equipped with a flame ionization detector (FID) and a HP-INNOWAX column $(30 \mathrm{~m} \times 320 \mu \mathrm{m} \times 8 \mu \mathrm{m}) . \mathrm{N}_{2}$ was used as carrier gas with a linear velocity of $1 \mathrm{ml} / \mathrm{min}$. The product was characterized by direct comparison with standard isoprene (TCI-EP, Tokyo, Japan). The peak area was converted to isoprene concentration by comparing with a standard curve plotted with a set of known concentration of isoprene. Then isoprene accumulation was measured every 30 min by GC.

\section{The comparison of production of isoprene in vitro and in vivo}

To compare isoprene production in shake flasks (in vivo) and in vitro, the engineered strain E. coli BL21(DE3)/ pYJM14/pACY-ISPS (Table 1) were cultured in $500 \mathrm{ml}$ sealed glass flasks containing $50 \mathrm{ml}$ of $\mathrm{M} 9$ medium supplemented with $10 \mathrm{~g} / \mathrm{L}$ glucose and $0.5 \mathrm{~g} / \mathrm{L}$ yeast extract, $34 \mu \mathrm{g} / \mathrm{mL}$ chloramphenicol, and $100 \mu \mathrm{g} / \mathrm{mL}$ Ampicillin. IPTG was added to the medium when the cell density 
$\mathrm{OD}_{600}$ reached to 0.6 and the cultures were performed at $30{ }^{\circ} \mathrm{C}$ in rotary shaker $(180 \mathrm{rpm})$. For isoprene production, the substrate $2.5 \mathrm{mM}$ mevalonate was added after the cell was induced and cultivated at $30^{\circ} \mathrm{C}$ for 4 and $16 \mathrm{~h}$ respectively. During the cultivation, samples of both the flask headspace and the culture were taken at multiple times points.

To set up similar enzyme levels in the in vitro system comparing to the in vivo control. The intracellular MVK concentration of the in vivo strain was firstly quantified using Quantity One Software (Biorad) described previously [19]. When $\mathrm{OD}_{600}$ reached 0.6, intracellular MVK concentration was about $0.4 \mu \mathrm{M}$. According to the optimized molarity ration for the in vitro system, $0.4 \mu \mathrm{M}$ of MVK, PMK, MVD, $0.8 \mu \mathrm{M}$ of IDI, $6.4 \mu \mathrm{M}$ of ISPS was added in the $50 \mathrm{ml}$ in vitro reaction system. $10 \mathrm{mM}$ ATP, $50 \mathrm{mM}$ potassium phosphate, $30 \mathrm{mM}$ potassium chloride, $10 \mathrm{mM}$ magnesium chloride, and $4 \mathrm{mM} \beta$-mercaptoethanol were also added in the reaction system. The reaction was initiated by addition of $2.5 \mathrm{mM}$ mevalonic acid which was made by the saponification of mevalonolactone with $\mathrm{KOH}$ at 1.05:1 (vol:vol) $\mathrm{KOH}$ :mevlonolactone for $30 \mathrm{~min}$ at $37^{\circ} \mathrm{C}$, and then incubated at $30{ }^{\circ} \mathrm{C}$ in rotary shaker $(180 \mathrm{rpm})$. During the cultivation, samples of both the flask headspace and the culture were taken at multiple times points.

\begin{abstract}
Abbreviations
MVA pathway: mevalonate pathway; MEP pathway: methylerythritol 4-phosphate pathway; MVK: mevalonate kinase; PMK: phosphomevalonate kinase; MVD: diphosphomevalonaet decarboxylase; IDI: isopentenyl diphosphate isomerase; ISPS: isoprene synthase; IPTG: isopropyl- $\beta$-d-thiogalactoside; GC: gas chromatography.
\end{abstract}

\section{Authors' contributions}

TC and HL conceived of the study, participated in its design, carried out the process control studies and drafted the manuscript. MS and NC participated in the coordination of this study, contributed to the data analysis and the process control studies. GZ and CX participated in its design and helped to draft the manuscript. MX and $\mathrm{HZ}$ conceived of the study, and participated in its design and coordination and helped to draft the manuscript. All authors read and approved the final manuscript.

\section{Author details \\ ${ }^{1}$ CAS Key Laboratory of Bio-based Materials, Qingdao Institute of Bioenergy and Bioprocess Technology, Chinese Academy of Sciences, No. 189 Songling Road, Laoshan District, Qingdao 266101, China. ${ }^{2}$ College of Chemical Engi- neering, Qingdao University of Science and Technology, Qingdao 266042, China. ${ }^{3}$ State Key Laboratory Base of Eco-Chemical Engineering, College of Chemistry and Molecular Engineering, Qingdao University of Science and Technology, Qingdao 266042, China.}

\section{Acknowledgements}

Not applicable.

\section{Competing interests}

The authors declare that they have no competing interests.

\section{Availability of data and materials}

The datasets supporting the conclusions of this article are included within the article.
Ethics approval and consent to participate

Not applicable. The manuscript does not report date from humans or animals.

\section{Funding}

The present study was supported by Shandong Province Natural Science Foundation (ZR2015BM011), Technology Development Project of Shandong Province (2016GSF121013), National Natural Science Foundation (21106170, 21376129, 21572242, 31670493)

Received: 26 September 2016 Accepted: 27 December 2016

Published online: 09 January 2017

\section{References}

1. Rabinovitch-Deere CA, Oliver JWK, Rodriguez GM, Atsumi S. Synthetic biology and metabolic engineering approaches to produce biofuels. Chem Rev. 2013;113(7):4611-32.

2. Keasling JD. Synthetic biology and the development of tools for metabolic engineering. Metab Eng. 2012;14(3):189-95.

3. Whited GM, Feher FJ, Benko DA. Development of a gas-phase bioprocess for isoprene-monomer production using metabolic pathway engineering. Ind Biotechnol. 2010;6(3):152-63.

4. Chang MCY, Keasling JD. Production of isoprenoid pharmaceuticals by engineered microbes. Nat Chem Biol. 2006;2(12):674-81.

5. George KW, Chen A, Jain A, Batth TS, Baidoo EEK, Wang G, Adams PD, Petzold CJ, Keasling JD, Lee TS. Correlation analysis of targeted proteins and metabolites to assess and engineer microbial isopentenol production. Biotechnol Bioeng. 2014;111(8):1648-58.

6. Gronenberg LS, Marcheschi RJ, Liao JC. Next generation biofuel engineering in prokaryotes. Curr Opin Chem Biol. 2013;17(3):462-71.

7. Zhang H, Liu Q, Cao Y, Feng X, Zheng Y, Zou H, Liu H, Yang J, Mo X. Microbial production of sabinene-a new terpene-based precursor of advanced biofuel. Microb Cell Fact. 2014;13(1):452-7.

8. Immethun CM, Hoynes-O'Connor AG, Balassy A, Moon TS. Microbial production of isoprenoids enabled by synthetic biology. Front Microbiol. 2013:4:75.

9. Martin VJ, Pitera DJ, Withers ST, Newman JD, Keasling JD. Engineering a mevalonate pathway in Escherichia coli for production of terpenoids. Nat Biotechnol. 2003;21(7):796-802.

10. Pitera DJ, Paddon CJ, Newman JD, Keasling JD. Balancing a heterologous mevalonate pathway for improved isoprenoid production in Escherichia coli. Metab Eng. 2007;9(2):193-207.

11. Ajikumar PK, Xiao W-H, Tyo KEJ, Wang Y, Simeon F, Leonard E, Mucha O, Phon TH, Pfeifer B, Stephanopoulos G. Isoprenoid pathway optimization for taxol precursor overproduction in Escherichia coli. Science. 2010;330(6000):70-4.

12. Dueber JE, Wu GC, Malmirchegini GR, Moon TS, Petzold CJ, Ullal AV, Prather KL, Keasling JD. Synthetic protein scaffolds provide modular control over metabolic flux. Nat Biotechnol. 2009;27(8):753-9.

13. Hodgman CE, Jewett MC. Cell-free synthetic biology: thinking outside the cell. Metab Eng. 2012;14(3):261-9.

14. Korman TP, Sahachartsiri B, Li D, Vinokur JM, Eisenberg D, Bowie JU. A synthetic biochemistry system for the in vitro production of isoprene from glycolysis intermediates. Protein Sci. 2014;23(5):576-85.

15. Opgenorth PH, Korman TP, Bowie JU. A synthetic biochemistry molecular purge valve module that maintains redox balance. Nat Commun. 2014;17(5):4113.

16. Yang J, Xian M, Su S, Zhao G, Nie Q, Jiang X, Zheng Y, Liu W. Enhancing production of bio-isoprene using hybrid MVA pathway and isoprene synthase in E. coli. PLoS ONE. 2012;7(4):e33509.

17. Ilmén M, Oja M, Huuskonen A, Lee S, Ruohonen L, Jung S. Identification of novel isoprene synthases through genome mining and expression in Escherichia coli. Metab Eng. 2015;31:153-62.

18. Yu X, Liu T, Zhu F, Khosla C. In vitro reconstitution and steady-state analysis of the fatty acid synthase from Escherichia coli. Proc Natl Acad Sci USA. 2015;108(46):18643-8.

19. Jin K, Peel AL, Mao XO, Xie L, Cottrell BA, Henshall DC, Greenberg DA. Increased hippocampal neurogenesis in Alzheimer's disease. Proc Natl Acad Sci USA. 2004;101:343-7. 